\title{
Broad spectrum resistance in Helicobacter pylori isolated from gastric biopsies of patients with dyspepsia in Cameroon and efflux-mediated multiresistance detection in MDR isolates
}

Laure Brigitte Kouitcheu Mabeku*, Bertrand Eyoum Bille1, Cromwell Tepap Zemnou', Lionel Danny Tali Nguefack ${ }^{1}$ and Hubert Leundji ${ }^{2}$

\begin{abstract}
Background: Antibiotic resistance is a leading cause of treatment failure in Helicobacter pylori infection. In Africa, there are very little data concerning the susceptibility of Helicobacter pylori isolates to antibiotics. The purpose of this study was to evaluate the resistance prevalence of Helicobacter pylori strains circulating in Cameroon, and to assess overexpression of efflux pump as a possible multi-drug resistance mechanisms.

Methods: A total of $140 \mathrm{H}$. pylori isolates were recovered from gastric biopsies of dyspeptic patients in two reference hospitals in Cameroon and analyzed for their antimicrobial susceptibility to amoxicillin, co-amoxiclav, ampicillin, penicillin, imipenem, metronidazole, rifabutin, erythromycin, clarithromycin, azithromycin, levofloxacin, ciprofloxacin, norfloxacin, tetracycline, doxycycline and minocycline. Antibiotic sensitivity was tested by disk diffusion method. Phe-Arg-naphthylamide (PAßN) was used as efflux pump inhibitor. INT broth microdilution method in supplemented Brain Heart Infusion broth was used to determine the MIC of ampicillin, amoxicillin, metronidazole, erythromycin, clarithromycin and doxycycline in the absence and the presence of PABN against 32 selected MDR isolates.

Results: Overall H. pylori resistance rate was $100 \%$ to ampicillin, penicillin and co-amoxiclav; $97.14 \%$ to amoxicillin, $97.85 \%$ to metronidazole, $47.85 \%$ to erythromycin, $13.57 \%$ to clarithromycin; $5,2.86$ and $0.71 \%$ to doxycycline, tetracycline and minocycline respectively. No resistance to azithromycin, rifabutin, imipenem, ciprofloxacin, norfloxacin and levofloxacin was detected among H. pylori isolates. Seventy percent (70\%) of the tested isolates elicited a multiple drugs resistance pattern; $42.57 \%$ double, $15.71 \%$ triple and $5.71 \%$ quadruple drugs resistance. Metronidazole and amoxicillin were more concerned with double resistance pattern (86.76\%). The spectrum of activity recorded with metronidazole, doxycycline, clarithromycin and erythromycin ranged from 0 to $100 \%$ in the absence to the presence of PABN against the tested MDR isolates. An 8 to 128-fold increase in potency was also noticed with these antibiotics in the presence of PAßN.

(Continued on next page)
\end{abstract}

\footnotetext{
* Correspondence: laurebkouitcheu@yahoo.fr

${ }^{1}$ Microbiology and Pharmacology Laboratory, Department of Biochemistry,

Faculty of Science, University of Dschang, P. O. Box, 67 Dschang, Cameroon

Full list of author information is available at the end of the article
}

(c) The Author(s). 2019 Open Access This article is distributed under the terms of the Creative Commons Attribution 4.0 International License (http://creativecommons.org/licenses/by/4.0/), which permits unrestricted use, distribution, and reproduction in any medium, provided you give appropriate credit to the original author(s) and the source, provide a link to the Creative Commons license, and indicate if changes were made. The Creative Commons Public Domain Dedication waiver (http://creativecommons.org/publicdomain/zero/1.0/) applies to the data made available in this article, unless otherwise stated. 
(Continued from previous page)

Conclusion: With regard to the high resistance rate to both amoxicillin and metronidazole, these drugs should be avoided as components of triple therapy in our milieu. In contrast, ciprofloxacin, norfloxacin, levofloxacin and tetracyclines could be used to achieve a better eradication rate and to reduce the risk of selection of $\mathrm{H}$. pylori resistant strains.

Keywords: Helicobacter pylori, Resistance prevalence, Antibiotics, Efflux pump, Cameroon

\section{Background}

Helicobacter pylori (H. pylori) is the only known pathogen that inhabits the gastric mucosa of almost half of the world's population [1, 2]. This bacterium can remain asymptomatic or can cause several gastrointestinal diseases, ranging in severity from superficial and chronic gastritis to duodenal ulceration and gastric adenocarcinoma [3].

In general, combined therapy is used to eradicate $H$. pylori infection [4]. Triple therapy, including two antibiotics, amoxicillin and clarithromycin, and a proton pump inhibitor given for a week has been recommended as the treatment of choice at several consensus conferences $[5,6]$. However, the efficiency of this standard regimen has decreased over the past decades, with the overall success rate of $74.6 \%$ in an intention-to-treat analysis and $82 \%$ in a perprotocol analysis [7]. In fact, the main reason for failure was found to be $H$ pylori resistance to one of the antibiotics used (that is, clarithromycin) $[8,9]$. Other treatments have also been proposed, including metronidazole, as well as tetracycline, fluoroquinolones, and rifamycins for which resistance has become an emerging issue [10, 11]. Resistance of $H$. pylori to the limited range of antibiotics that have efficacy in its treatment can severely affect attempts to eradicate this bacteria. Therefore, susceptibility testing of $H$. pylori is important for the eradication of this organism. An additional advantage of susceptibility testing is that it may reduce the risk of $H$. pylori resistance [12]. As a result, the choice of regimens for patients should be based on knowledge of local resistance patterns and antibiotic used [13].

Bacterial resistance to antimicrobial agents may be caused by overexpression of multi-drug resistance (MDR) efflux pumps [14, 15]. Active efflux was first described in 1980 , as a causative mechanism of resistance to tetracyclines [16]. It has subsequently been found to be a widespread mechanism conferring to both Gram-positive and Gram-negative organisms the capacity to expel antibiotics from all the major structural classes [15, 17]. Among Gram-negative bacteria, many of these MDR efflux pumps belong to the resistance-nodulation-cell division (RND) type family of tripartite efflux pumps [18]. MDR in selected Gram-negative bacteria has been shown to be reversible by using compounds like Phe-Arg-naphthylamide $(\mathrm{PA} \beta \mathrm{N})$ or other small N-heterocyclic organic compounds thought to inhibit RND type efflux pump activity through unknown mechanisms [19-22].
H. pylori infection seems to be common in Cameroon: a study carried out in 2004 had demonstrated a prevalence of $92.2 \%$ among apparently healthy children in the Buea and Limbe health districts of Cameroon [23]; a hospital-based survey conducted in 2013 has revealed an overall prevalence of $72.5 \%(124 / 171)$ in Yaoundé, center region of Cameroon [24]. Still in the same region in 2015, a prevalence of $79.3 \%$ of the pathogen was documented among children and adolescents from the age range of 6 to 18 years old with peptic ulcer disease [25]. In 2016, Kouitcheu et al. [26] found a seroprevalence of $64.34 \%$ among 205 patients aged 35 years and older with symptoms of dyspepsia or other symptoms referable to the proximal alimentary tract in the littoral region of Cameroon. Even though $H$. pylori infection is common in Cameroon, there is no regional surveillance programs that monitor the evolution of $H$. pylori resistance in order to allow timely adaptation of the treatment regimens in the country. The present study is therefore aimed at evaluating the susceptibility of clinical isolates of $H$. pylori circulating in Cameroon to different antibiotics used in the treatment of this infection, in a bid to identify potential optimal therapeutic regimen for this infection adapted to Cameroon. As a causative mechanism of resistance, the spectrum of action of these antibiotics regarding the role of efflux pumps in their activity was also investigated by using multi drug resistant strains selected and Phe-Arg-naphthylamide (PAßN) a previously described efflux pump inhibitor.

\section{Methods \\ Selection of subjects}

This was a cross sectional study carried out at the gastroenterology Department of Laquintinie Hospital and General Hospital of Douala-Cameroon, from April 2013 to June 2015. All patients aged 15 to 90 years old, either sex, attending the Gastroenterology Department at the selected health centers with gastritis, gastric and duodenal ulcer undergoing endoscopy were recruited. Exclusion criteria were, (1) Non-cooperative patients who refused to give their consent or to participate to the study; (2) patients with a history of $H$. pylori eradication treatment; (3) patients with a history of antibiotics consumption within the last fourth weeks. Gastric biopsies were collected from the enrolled patients, ground and about two drops of homogenates were 
inoculated into supplemented Columbia Agar (Columbia Agar $+5 \%(\mathrm{v} / \mathrm{v})$ lacked horse blood and 1\% (v/v) Vitox (CD-Vitox)). The inoculated culture media were incubated at $37^{\circ} \mathrm{C}$ under microaerophilic conditions (CampyGen gas pack) for 7 days. Isolates that exhibited Gram negative curved rods on Gram stain reaction and were positive for catalase, oxidase and urease tests were considered as $H$. pylori [27, 28]. Confirmed isolates were suspended in eppendorf tubes containing Brain Heart Infusion broth supplemented with $5 \%$ horse serum (BHI-serum) with $30 \%$ glycerol and stored at $-80^{\circ} \mathrm{C}$ until future use. The study was approved by both local ethical committee (Approval $\mathrm{N}^{0}$ 425/AR/MINSANTE/HLD/SCM/CR) and the national institutional Review Board, the National Ethical Committee on human health research in Cameroon (ethical clearance $\mathrm{N}^{0}$ 2014/03/425/L/CNESRH/SP).A standard control strain NCTC 11638 was also used to confirm the identification and for antimicrobial assays.

\section{Bacterial strains}

One hundred and forty (140) $\mathrm{H}$. pylori isolates were recovered from gastric biopsies of eligible patients and subjected to antimicrobial assays in this study. All isolates were removed from storage at $-80^{\circ} \mathrm{C}$ and subcultured on supplemented Columbia Agar (Columbia Agar $+5 \%$ (v/v) lacked horse blood and 1\% (v/v) Vitox (CD-Vitox)). Subcultures were incubated at $37^{\circ} \mathrm{C}$ under microaerophilic conditions (CampyGen gas pack) for 3 days and for two passages to ensure reliable growth. Gram staining, rapid urease and the catalase/oxydase tests were performed to confirm the identification $[28,29]$.

\section{Antibiotic susceptibility test}

Antibiotic susceptibility studies were performed by disc diffusion (Kirby-Bauer) method according to Clinical Laboratory Standards Institute (CLSI, 2015) [29]. The following antibiotic disks were tested: amoxicillin $(10 \mu \mathrm{g})$, co-amoxiclav $(30 \mu \mathrm{g})$, ampicillin $(10 \mu \mathrm{g})$, penicillin $(10 \mathrm{U})$, imipenem $(10 \mu \mathrm{g})$, metronidazole $(5 \mu \mathrm{g})$, rifabutin $(5 \mu \mathrm{g})$, erythromycin $(15 \mu \mathrm{g})$, clarithromycin $(15 \mu \mathrm{g})$, azithromycin $(15 \mu \mathrm{g})$, levofloxacin $(5 \mu \mathrm{g})$, ciprofloxacin $(30 \mu \mathrm{g})$, norfloxacin $(30 \mu \mathrm{g})$, tetracycline $(30 \mu \mathrm{g})$, doxycycline $(30 \mu \mathrm{g})$ and minocycline $(30 \mu \mathrm{g})$ (Biomaxima). H. pylori inocula prepared at McFarlands turbidity standard $3\left(6 \times 10^{8}\right.$ CFU/ml) by suspending 48 - $\mathrm{h}$ colonies in $2 \mathrm{ml}$-sterile normal saline was used to seed each prepared and dried supplemented Columbia agar plate. The discs were arranged and firmly pressed on the agar surface of each seeded plate. The plates were incubated under microaerophilic conditions at $37^{\circ} \mathrm{C}$ for 48 to $72 \mathrm{~h}$. The microaerophilic conditions were generated using CampyGen in an airtight anaerobic jar (Oxoid). Zone sizes were measured and the isolates were classified as sensitive or resistant according to the interpretative criteria for CLSI guidelines (2012) and CASFM (2017) [30, 31]. The isolate exhibited a multidrug resistance phenotype were also noticed. The experiment was performed in triplicate and the mean zone diameters of inhibition recorded for each antibiotic.

\section{Assessment of MDR reversal activity in MDR H. pylori isolates: MIC determination of antibiotics alone and in combination with efflux pump inhibitor}

In order to determine a possible mechanisms involved in resistance pattern of the tested clinical isolate against antibiotics used, overexpression of MDR efflux pumps in the isolated $H$. pylori strains was investigated using PheArg-naphthylamide (PAßN). Thirty two (32) isolates which elicited triple or quadruple drug-multi resistance pattern to the tested antibiotics according to the above test were selected. Selected MDR isolates were tested for their susceptibilities to antibiotics amoxicillin (AMO), ampicillin (AMP), clarithromycin (CLR), erythromycin (ERY), metronidazole (MET), tetracycline (TET) and ciprofloxacin (CIP) alone and then in the presence of $\mathrm{PA} N \mathrm{~N}$ at a final concentration of $20 \mu \mathrm{g} / \mathrm{ml}$ as described previously [32]. The MICs were carried out by the INT broth microdilution method [33, 34] using Brain Heart Infusion broth supplemented with $5 \%$ horse serum (BHI-serum) and various concentrations of antibiotics. Two fold dilutions of each selected antibiotics were prepared in the test wells in BHI -serum. The ranges of antibiotic concentrations that were used in this study were as follows: amoxicillin (AMO, 0.03125-128 $\mu \mathrm{g} / \mathrm{ml}$ ), ampicillin (AMP, 0.03125-128 $\mu \mathrm{g} / \mathrm{ml}$ ), Clarithromycin (CLR, 0.0625-16 $\mu \mathrm{g} / \mathrm{ml}$ ), erythromycin (ERY, 0.125$32 \mu \mathrm{g} / \mathrm{ml}$ ), metronidazole (MET, $0.5-128 \mu \mathrm{g} / \mathrm{ml}$ ) and doxycycline (DOX, $0.0625-32 \mu \mathrm{g} / \mathrm{ml}$ ). All antimicrobial agents were purchased from Sigma-Aldrich, Germany. The selected MDR H. pylori isolates were removed from freezer, thawed and subcultured on supplemented Columbia Agar without antibiotics and incubated under microaerophilic conditions at $37^{\circ} \mathrm{C}$ for 3 days. After a lawn of growth appeared, MDR bacterial colonies were suspended in sterile saline at a density equivalent to 3 McFarland's standard. One hundred microliter of each prepared inoculum was added to $100 \mu \mathrm{l}$ of the antibioticcontaining culture medium or antibiotic $+\mathrm{PA} ß \mathrm{~N}$-containing culture medium. Control wells were prepared with culture medium and MDR bacterial suspension, and broth only. The plates were covered with a sterile plate sealer; the contents of the wells were mixed with a shaker and incubated for 3 days at $37{ }^{\circ} \mathrm{C}$ under microaerophilic conditions. After incubation, $40 \mu \mathrm{l}$ of $0.2 \mathrm{mg} /$ $\mathrm{ml}$ INT was added per well and incubated at $37{ }^{\circ} \mathrm{C}$ for $30 \mathrm{~min}$. Living bacteria reduced the yellow dye to pink. The MIC value of antibiotic defined as its lowest concentration which completely inhibited visible bacterial growth at $37^{\circ} \mathrm{C}$ after $72 \mathrm{~h}$ was determined in the 
presence and in the absence of efflux pump inhibitor. Each MIC was determined in triplicate and the mean values were recorded. Then, the fractional inhibitory concentration (FIC) of each combination was calculated as the ratio of MIC of antibiotic with efflux pump inhibitor versus MIC of antibiotic alone. Resistance was defined in accordance with the European Committee on Antimicrobial Susceptibility Testing (EUCAST) guidelines [35]: amoxicillin, ampicillin ( $\mathrm{MIC}>0.125 \mu \mathrm{g} / \mathrm{ml})$, clarithromycin ( $\mathrm{MIC}>0.5 \mu \mathrm{g} / \mathrm{ml}$ ), erythromycin (MIC > $1 \mu \mathrm{g} / \mathrm{ml}$ ), tetracycline, doxycycline (MIC $>1 \mu \mathrm{g} / \mathrm{ml}$ ); metronidazole (MIC $>4 \mu \mathrm{g} / \mathrm{ml})$ [36].

\section{Results}

\section{Resistance profile of isolated $H$. pylori strains to antibiotics}

In this study, the susceptibility of $140 \mathrm{H}$. pylori clinical isolates was evaluated against 16 antibiotics belonged to six class and they were classified according to their resistance profile to the tested drugs (Tables 1 and 2, Fig. 1). None of the tested strains elicited a $100 \%$ susceptibility to the overall antibiotics used. However, they did not showed any resistance to rifabutin, imipenem, azithromycin, ciprofloxacin, norfloxacin and levofloxacin (Table 2). Resistance rates recorded against the tested antibiotics were as follows: highest resistance rate (100 to $97.85 \%$ ) to metronidazole and penicillin group (ampicillin, penicillin, coamoxiclav, amoxicillin); 47.85 and $13.57 \%$ to erythromycin and clarithromycin respectively. Antibiotic from tetracyclines (tetracycline: $2.86 \%$, doxycycline: $5 \%$ and minocycline: $0.71 \%$ ) were slightly affected by resistance. Since there was a high disparity between the resistance rate of imipenem $(0 \%)$ and that of the other $\beta$ lactam antibiotics tested (ampicillin: 100\%, penicillin: 100\%, co-amoxiclav: $100 \%$ and amoxicillin: 97.14\%), this class were divided in penicillin and carbopemems subgroups, and the resistance prevalence of this two subgroups were not joined in statistical analysis. So, the peak of resistance was detected with metronidazole (imidazoles class) and penicillin's subgroup with respective resistance rate of 99.28 and $97.85 \%$, followed by macrolides with $20.47 \%$. However, none of the tested strains were resistance to azithromycin one of the three macrolides tested (Fig. 1). Rifabutin, the only antibiotic of the rifamycine class used and all the fluoroquinolone tested showed a $100 \%$ activity against the tested isolates.

\section{Multiple resistance pattern of isolated $H$. pylori strains}

Out of the $140 \mathrm{H}$. pylori isolates tested, 98 elicited a multiple resistance pattern, given the overall multidrug resistance rate of $70 \%(98 / 140)$. The incriminated antibiotics classes were imidazole, penicillin, macrolides and tetracyclines. Table 3 summarizes the multi-drug resistant pattern of tested $H$. pylori isolates; 68 (48.57\%) elicited double, $22(15.71 \%)$ triple and 8 (5.71\%) quadruple drugs resistance. Double resistance were more frequent with metronidazole and amoxicillin $\left(\mathrm{MET}^{\mathrm{R}} / \mathrm{AMO}^{\mathrm{R}}\right)$ which represented $86.76 \%(59 / 68)$ of this type of multi-drugs resistance pattern, followed by $\mathrm{MET}^{\mathrm{R}} / \mathrm{CLR}^{\mathrm{R}}, \mathrm{MET}^{\mathrm{R}} / \mathrm{TET}^{\mathrm{R}}$ and $\mathrm{CLR}^{\mathrm{R}} / \mathrm{AMO}^{\mathrm{R}}$. As regards triple drug resistance, metronidazole, clarithromycin and amoxicillin $\left(\mathrm{MET}^{\mathrm{R}} / \mathrm{CLR}^{\mathrm{R}} /\right.$ $\mathrm{AMO}^{\mathrm{R}}$ ) were more concerned and represented 95.45\%

Table 1 Screening of antibiotics for anti-H. pylori activity using disc diffusion method

\begin{tabular}{llll}
\hline Antibiotics & Breakpoint & Mean zone diameter $(\mathrm{mm})$ & Inhibition diameter range $(\mathrm{mm})$ \\
\hline Amoxicillin (AMO) & $\geq 21<16$ & $6.21 \pm 1.35$ & $6-12$ \\
Co-Amoxiclav (AMC) & $\geq 23<16$ & $6.59 \pm 3.02$ & $6-28$ \\
Penicillin (PEN) & $\geq 23<16$ & $6.125 \pm 0.5$ & $6-8$ \\
Imipenem (IMP) & $\geq 29<18$ & $6.25 \pm 0.61$ & $6-8$ \\
Metronidazole (MET) & $\geq 24<17$ & $22 \pm 1.63$ & $20-24$ \\
Clarithromycin (CLR) & $\geq$ ND $<21$ & $6.49 \pm 2.43$ & $6-22$ \\
Azithromycin (AZT) & $\geq 22<16$ & $22.91 \pm 4.25$ & $10-30$ \\
Erythromycin (ERY) & $\geq 22<16$ & $29.89 \pm 6.25$ & $18-40$ \\
Rifabutin (RIF) & $\geq 22<17$ & $17.59 \pm 6.58$ & $6-30$ \\
Tetracycline (TET) & ND $<17$ & $20.61 \pm 1.93$ & $18-32$ \\
Doxycycline (DOX) & $\geq 19<17$ & $20.83 \pm 3.11$ & $12-30$ \\
Minocycline (MIN) & $\geq 19<17$ & $22.55 \pm 4.53$ & $16-34$ \\
Levofloxacin (LEV) & $\geq 19<17$ & $23.08 \pm 2.29$ & $18-28$ \\
Ciprofloxacin (CIP) & $\geq 25<20$ & $31.40 \pm 3.99$ & $22-40$ \\
Norfloxacin (NOR) & $\geq 25<12$ & $31.20 \pm 3.42$ & $20-40$ \\
Ampicillin (AMP) & $\geq 25<20$ & $28.38 \pm 2.27$ & $22-32$
\end{tabular}

Data are mean \pm SD of 140 determinations for each antibiotic 
Table 2 Resistance of Helicobacter pylori clinical isolates to antibiotics

\begin{tabular}{ll}
\hline Antibiotics & Resistance No (\%) \\
\hline Ampicillin (AMP) & $140(100)$ \\
Amoxicillin (AMO) & $136(97.14)$ \\
Co-Amoxiclav (AMC) & $140(100)$ \\
Penicillin (PEN) & $140(100)$ \\
Imipenem (IMP) & $0(0)$ \\
Metronidazole (MET) & $137(97.85)$ \\
Clarithromycin (CLR) & $19(13.57)$ \\
Azithromycin (AZT) & $0(0)$ \\
Erythromycin (ERY) & $67(47.85)$ \\
Rifabutin (RIF) & $0(0)$ \\
Tetracycline (TET) & $4(2.86)$ \\
Doxycycline (DOX) & $7(5)$ \\
Minocycline (MIN) & $1(0.71)$ \\
Levofloxacin (LEV) & $0(0)$ \\
Ciprofloxacin (CIP) & $0(0)$ \\
Norfloxacin (NOR) & $0(0)$ \\
\hline
\end{tabular}

No: Number of resistant isolate to each antibiotic

(21/22) of this type of multidrug resistance pattern. Quadruple drugs resistance was the maximum and the less multi-drugs resistance pattern detected and metronidazole, tetracycline, clarithromycin and amoxicillin were combined.

\section{Efflux-mediated antimicrobial resistance}

As possible mechanisms involved in resistance pattern of the tested clinical isolates against antibiotics used, overexpression of MDR efflux pumps in the isolated $H$. pylori strains was investigated using Phe-Arg-naphthylamide
(PAßN). The susceptibility to antibiotics of selected MDR isolates (32) was evaluated in the presence and absence of the PAßN. The selected antibiotics were ampicillin, amoxicillin, metronidazole, erythromycin, clarithromycin and doxycycline to which the tested isolate displayed a resistance prevalence of 100, 97.14, 97.85, 47.85, 13.57 and 5\% respectively. Table 4 summarizes the susceptibility of the selected MDR H. pylori isolate to antibiotics in the absence and presence of PA $\mathrm{N}$. The activity spectrum of amoxicillin and ampicillin was not affected in the presence of the efflux pumps inhibitor. However, our results showed that this inhibitor (PAßN) have improved the activity of $67 \%(4 / 6)$ of the antibiotics tested (that is metronidazole, doxycycline, clarithromycin and erythromycin). The spectrum of activity recorded with metronidazole, doxycycline, clarithromycin and erythromycin against the tested MDR $H$. pylori strains ranged in the absence to the presence of the inhibitor from 0 to $34.37 \%$; from 40 to $100 \%$; from 0 to $100 \%$ and from 6.90 to $100 \%$ respectively (Table 4 ).

An increase in potency of 128 and 64-fold was observed with metronidazole in $3.125 \%(1 / 32)$ of the selected MDR isolates, that of clarithromycin was 64 and 40 -fold in $40 \%(2 / 5)$ of the selected isolates, 32 to 40 fold with erythromycin in $34.48 \%(10 / 29)$ of the tested isolates and 8-fold increase in potency with doxycycline in $60 \%(3 / 5)$ of the MDR isolates tested (Table 4).

\section{Discussion}

Appropriate selection of antibiotic regimen for treatment of $H$. pylori prior to initiation therapy decreases the exposure to ineffective antibiotics and increases the rate of cure. This highlights the need for susceptibility testing of $H$. pylori isolates prior to the eradication of infection.

In the present investigation, we tested the resistant profile of $H$. pylori isolated from dyspeptic patients attending

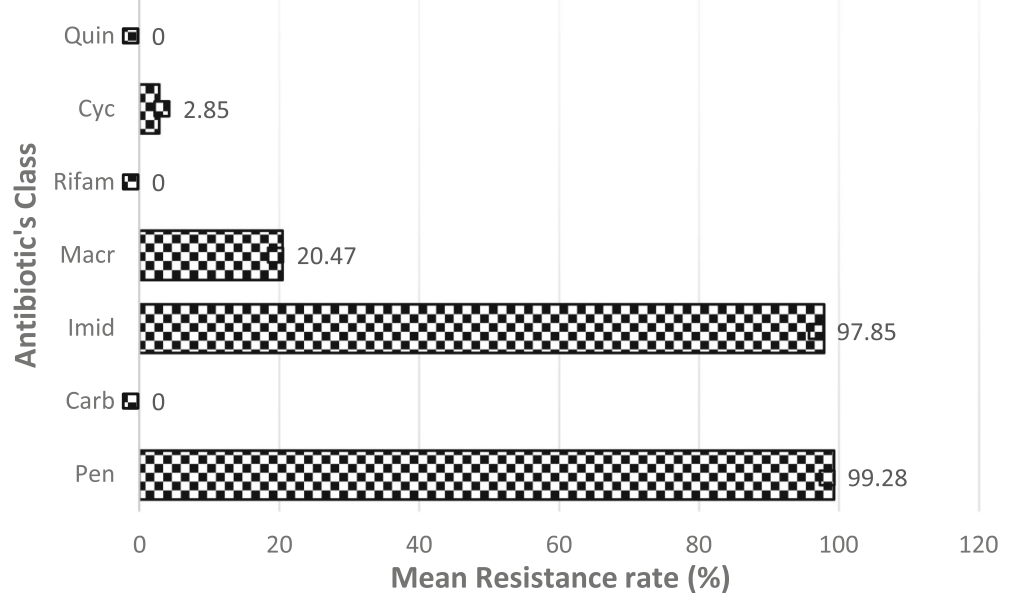

Fig. 1 Resistance profile of H. pylori clinical isolates to class of antibiotics tested. Penicillin: Pen, Carbopenems: Carb, Imidazole: Imid, Macrolides: Macr, Rifamycines: Rifam, Tetracyclines: Cyc, Quinolones: Quin 
Table 3 Multi-drugs resistance pattern of Helicobacter pylori clinical isolates to antibiotic

\begin{tabular}{|c|c|c|c|c|c|c|c|c|}
\hline \multirow{2}{*}{$\begin{array}{l}\text { Multi- } \\
\text { resistance } \\
\text { pattern }\end{array}$} & \multicolumn{4}{|c|}{ Double drugs resistance } & \multicolumn{2}{|c|}{ Triple drugs resistance } & \multirow{2}{*}{$\begin{array}{l}\text { Quadruple drugs resistance } \\
M T^{R} T E T^{R} C L R^{R} A M O^{R}\end{array}$} & \multirow{2}{*}{$\begin{array}{l}\text { Overall } \\
\text { multi- } \\
\text { drugs } \\
\text { resistance }\end{array}$} \\
\hline & $\overline{M E T^{R}} \mathrm{AMO}^{\mathrm{R}}$ & $\mathrm{MET}^{\mathrm{R}} \mathrm{CLR} \mathrm{R}^{\mathrm{R}}$ & $C L R^{R} A M O^{R}$ & $\mathrm{MET}^{\mathrm{R}} / \mathrm{TET}^{\mathrm{R}}$ & $\overline{M T^{R}{ }^{2} R^{R} A M O^{R}}$ & $M{ }^{R} T^{R} T^{R} T^{R} A M O^{R}$ & & \\
\hline Number (\%) & $59(42.14)$ & $6(4.28)$ & $1(0.71)$ & $2(1.42)$ & $21(15)$ & $1(0.71)$ & $8(5.71)$ & \\
\hline Total (\%) & $68(48.57)$ & & & & $22(15.71)$ & & $8(5.71)$ & $98(70)$ \\
\hline
\end{tabular}

Table $4 \mathrm{MIC}$ value of antibiotics $(\mu \mathrm{g} / \mathrm{ml})$ in absence and in presence of the efflux pump inhibitor (PAßN)

\begin{tabular}{|c|c|c|c|c|c|c|c|c|c|c|c|c|c|c|c|c|c|c|}
\hline \multirow{3}{*}{$\begin{array}{l}\text { H. pylori clinical } \\
\text { isolate }\end{array}$} & \multicolumn{18}{|c|}{ Antibiotics } \\
\hline & \multicolumn{3}{|c|}{$\overline{\mathrm{MET}}$} & \multicolumn{3}{|c|}{ CLR } & \multicolumn{3}{|l|}{ ERY } & \multicolumn{3}{|c|}{ AMP } & \multicolumn{3}{|c|}{$\mathrm{AMO}$} & \multicolumn{3}{|c|}{ DOX } \\
\hline & A & P & $F$ & $A$ & P & $\mathrm{F}$ & $A$ & $P$ & $\mathrm{~F}$ & $A$ & $P$ & $\mathrm{~F}$ & $A$ & P & $\mathrm{F}$ & $A$ & $P$ & $\mathrm{~F}$ \\
\hline $\mathrm{HP}$ & 128 & 4 & 31.2 & 16 & 0.25 & 15.2 & 8 & $<0.2$ & 31.2 & $\neq$ & $\neq$ & / & $\neq$ & $\neq$ & I & 2 & $<0.2$ & 125 \\
\hline HP002 & 128 & 4 & 31.2 & 2 & $<0.2$ & 125 & 2 & $<0.2$ & 125 & $\neq$ & $\neq$ & I & $\neq$ & $\neq$ & / & - & - & - \\
\hline HP0094 & 128 & 8 & 62.5 & - & - & - & 4 & $<0.2$ & 62.5 & $\neq$ & $\neq$ & / & $\neq$ & $\neq$ & / & 2 & $<0.2$ & 125 \\
\hline HP0072 & 128 & 4 & 125 & - & - & - & 2 & 0.5 & 250 & $\neq$ & $\neq$ & / & $\neq$ & $\neq$ & / & - & - & - \\
\hline HP0099 & 128 & 16 & 125 & - & - & - & 2 & 0.25 & 125 & $\neq$ & $\neq$ & / & $\neq$ & $\neq$ & / & - & - & - \\
\hline HP0095 & 128 & 2 & 15.6 & 4 & $<0.2$ & 62.5 & 8 & 0.25 & 31.2 & $\neq$ & $\neq$ & / & $\neq$ & $\neq$ & / & - & - & - \\
\hline HP00115 & 128 & 8 & 62.5 & 1 & $<0.2$ & 250 & 2 & $<0.2$ & 125 & $\neq$ & $\neq$ & / & $\neq$ & $\neq$ & / & - & - & - \\
\hline HP00117 & 128 & 8 & 62.5 & 8 & $<0.2$ & 31.2 & 8 & 0.25 & 31.2 & $\neq$ & $\neq$ & / & $\neq$ & $\neq$ & / & - & - & - \\
\hline HP00105 & 128 & 4 & 31.2 & - & - & - & 8 & 0.25 & 31.2 & $\neq$ & $\neq$ & / & $\neq$ & $\neq$ & / & 1 & $<0.2$ & 250 \\
\hline HP0060 & 128 & 16 & 125 & - & - & - & 1 & 0.25 & 250 & $\neq$ & $\neq$ & / & $\neq$ & $\neq$ & / & - & - & - \\
\hline HP0063 & 128 & 8 & 62.5 & - & - & - & 8 & $<0.2$ & 31.2 & $\neq$ & $\neq$ & / & - & - & - & - & - & - \\
\hline HP0050 & 128 & 8 & 62.5 & - & - & - & 4 & $<0.2$ & 62.5 & $\neq$ & $\neq$ & / & $\neq$ & $\neq$ & / & - & - & - \\
\hline HP0048 & 128 & 16 & 125 & - & - & - & 4 & $<0.2$ & 62.5 & $\neq$ & $\neq$ & / & $\neq$ & $\neq$ & / & - & - & - \\
\hline HP0069 & 128 & 4 & 31.2 & - & - & - & 2 & 0.5 & 125 & $\neq$ & $\neq$ & / & $\neq$ & $\neq$ & / & - & - & - \\
\hline HP0070 & 128 & 4 & 31.2 & - & - & - & 4 & $<0.2$ & 62.5 & $\neq$ & $\neq$ & / & $\neq$ & $\neq$ & / & 0.5 & $<0.2$ & 500 \\
\hline HP0055 & 128 & 4 & 31.2 & - & - & - & 8 & 1 & 125 & $\neq$ & $\neq$ & / & $\neq$ & $\neq$ & / & 2 & $<0.25$ & 125 \\
\hline HP00102HD & 128 & 8 & 62.5 & - & - & - & 4 & 0.25 & 31.2 & $\neq$ & $\neq$ & / & $\neq$ & $\neq$ & / & - & - & - \\
\hline HP00132 & 128 & 16 & 125 & - & - & - & 1 & 0.25 & 250 & $\neq$ & $\neq$ & / & $\neq$ & $\neq$ & 1 & - & - & - \\
\hline HP00131 & $\neq$ & 8 & 62.5 & - & - & - & 8 & 0.25 & 31.2 & $\neq$ & $\neq$ & / & $\neq$ & $\neq$ & / & - & - & - \\
\hline HР00133 & 128 & 16 & 125 & - & - & - & - & & & $\neq$ & $\neq$ & / & $\neq$ & $\neq$ & / & - & - & - \\
\hline HP0045HGD & 128 & 16 & 125 & - & - & - & 8 & $<0.2$ & 31.25 & $\neq$ & $\neq$ & / & $\neq$ & $\neq$ & / & - & - & - \\
\hline HP0098HGD & 128 & 8 & 62.5 & - & - & - & - & & & $\neq$ & $\neq$ & / & $\neq$ & $\neq$ & 1 & - & - & - \\
\hline HP00100HD & 128 & 8 & 62.5 & - & - & - & 4 & 0.25 & 62.5 & $\neq$ & $\neq$ & / & $\neq$ & $\neq$ & I & - & - & - \\
\hline HP0064 & $\neq$ & 1 & 7.8 & - & - & - & 8 & $<0.2$ & 31.2 & $\neq$ & $\neq$ & / & $\neq$ & $\neq$ & / & - & - & - \\
\hline HP0065 & 128 & 8 & 62.5 & - & - & - & - & & & $\neq$ & $\neq$ & / & $\neq$ & $\neq$ & / & - & - & - \\
\hline HP0066 & 128 & 16 & 125 & - & - & - & 8 & $<0.2$ & 31.2 & $\neq$ & $\neq$ & / & $\neq$ & $\neq$ & / & - & - & - \\
\hline HP0063HGD & $\neq$ & 8 & 62.5 & - & - & - & 4 & 0.25 & 62.5 & $\neq$ & $\neq$ & / & $\neq$ & $\neq$ & / & - & - & - \\
\hline HP0044HGD & 128 & 16 & 125 & - & - & - & 4 & 0.25 & 62.5 & $\neq$ & $\neq$ & / & - & - & & - & - & - \\
\hline HP0046HGD & 128 & 16 & 125 & - & - & - & 4 & 0.25 & 62.5 & $\neq$ & $\neq$ & / & $\neq$ & $\neq$ & / & - & - & - \\
\hline HP0036 & 128 & 4 & 31.25 & - & - & - & 8 & 0.25 & 31.2 & $\neq$ & $\neq$ & / & $\neq$ & $\neq$ & / & - & - & - \\
\hline HP0061 & 128 & 16 & 125 & - & - & - & 8 & 0.5 & 62.5 & $\neq$ & $\neq$ & / & 128 & 128 & 1 & - & - & - \\
\hline HP0062 & $\neq$ & 4 & 31.2 & - & - & - & 8 & 0.5 & 62.5 & $\neq$ & $\neq$ & / & $\neq$ & $\neq$ & / & - & - & - \\
\hline Activity spectrum (\%) & 0 & 34.4 & & 0 & 100 & & 6.9 & 100 & & 0 & 0 & & 0 & 0 & & 40 & 100 & \\
\hline
\end{tabular}


Gastroenterology Department of two reference health center in Douala-Cameroon, to sixteen routinely used drugs including ampicillin, amoxicillin, co-amoxiclav, penicillin, imipenem, metronidazole, rifabutin, clarithromycin, erythromycin, azithromycin, tetracycline, doxycycline, minocycline, ciprofloxacin, levofloxacin and norfloxacin. Our findings showed that $97.85 \%$ (137/140) of the tested H. pylori clinical isolates were resistant to metronidazole. Metronidazole is a frequently used drug in Cameroon for other infections like parasitic or genital infections. Hence, the high dose metronidazole use in vivo or abuse of this inexpensive drug may contribute to the increase in metronidazole resistance and therefore it is not unexpected to find such a high level of resistance in our milieu. The use of nitroimidazole for dental infections may also add to selection pressure. The present resistance prevalence is comparable to the 93.2 and $90 \%$ resistance rate to MET reported in Africa respectively in Cameroon in 2006 [37] and in Senegal in 2000 [38]. This high prevalence to metronidazole is as might be expected in developing countries. In a Systematic Review reporting data of 31 studies (17 European, 10 Asian, 2 African and 2 American studies) on $H$. pylori antibiotic resistance from 1993 to 2009, the primary metronidazole resistance detected was $92.4 \%$ in Africa, $44.1 \%$ in America, $37.1 \%$ in Asia and $17.0 \%$ in Europe [39]; with a statistical significant difference among the four geographic areas. The differences between the resistance rates may reflect the variation in metronidazole usage between continental areas and countries.

Amoxicillin is the only $\beta$-lactam used to treat $H$. pylori infection and it is included in most current therapeutic regimens. In the present study, the amoxicillin resistance rate was $97.14 \%$. Our finding is slightly similar to the 85.6\% reported by Ndip et al. in 2006 in Cameroon [37]. However the present AMO rate is in contrast with other studies reporting that acquired resistances to AMO are extremely rare. In fact, in Europe, available data from a study found a prevalence rate of $1.1 \%$ in Bulgaria [40]; $2.2 \%$ in a study enrolling 352 patients in Alaska [41]. Similarly, the prevalence of amoxicillin resistance in Asian countries still low, ranging from $0 \%$ in Japan [42], 8.8\% in Korea [43] and 1\% [44] in Taiwan. Also, in Africa, a study from Senegal enrolling 40 patients reports an absent of amoxicillin resistance [38]. The high rate of resistance in the present study, in comparison with other studies may be due to the use of this drug in a disproportionate manner in our setting.

Three macrolide were used in this study; erythromycin, clarithromycin and azithromycin. Our finding showed a resistance prevalence of 47.85 and $13.57 \%$ respectively for erythromycin and clarithromycin. No resistance was detected with azithromycin. Among macrolides, clarithromycin is widely used for $H$. pylori eradication in combination with a proton pump inhibitor with or without a second antibiotic. The present clarithromycin resistance (13.57\%) is lower than early clarithromycin resistance prevalence (44.7) detected in Cameroon in 2006 [37], in America (29.3\%) [39], in Japan (40.7\%) [42], in Italy (36.7\%) [45] and in Spain (49.2\%) [46]. However, it is comparable to the resistance rate range of 11 to $15 \%$ reported in 2 studies performed in Iran [47, 48], in Bulgaria [40], in Denmark [49], in Italy [50], in Korea [43] and in Taiwan [44]. The differences between the resistance rates may reflect the variation in clarithromycin usage between countries. Since high cost of clarithromycin limits the use of this drug in Cameroon, finding such resistant isolates may be partially explained by the primary resistance of $H$. pylori to clarithromycin. Unlike with clarithromycin, the tested isolates did not showed any resistance to azithromycin, suggesting that this later drug could be used instead of clarithromycin. But, this cannot be recommended, since macrolide cross-resistance prevents the use of this entire class of antimicrobials when clarithromycin resistance is present. With regards of the resistance rate to erythromycin, this antibiotics may contribute on the selection of resistant of the tested strains to clarithromycin.

Tetracyclines are currently used in the treatment of $H$. pylori infection as part of quadruple therapy. In this study, resistance rates of $2.86,5$ and $0.71 \%$ were detected to tetracycline, doxycycline and minocycline respectively, suggesting that tetracyclines were slightly affected by resistance. The present low resistance rate of the tested clinical isolates to tetracyclines $(2.86 \%)$ indicates the importance of this drug in eradicating $H$. pylori strains circulating in Cameroon. Tetracyclines are not routinely used in H. pylori eradication regimens, therefore finding such a low resistance rate is not unexpected. The present resistance prevalence is in accordance with previous studies reporting that the overall resistance of $H$. pylori to tetracycline is estimated to be around 2\% [51]. In fact, the overall tetracycline prevalence rate did not significantly differ between Europe (2.1\%), Asia (2.4\%) and America (2.7\%) [39]. In contrast, increased values were found in Korea (8.8\%) [43]; resistance rates up to $20 \%$ in Iran (20\%) [48] and in Chile (26.8\%) [52] and a significant higher resistance of $43.9 \%$ in Cameroon [37]. The differences between the resistance rates may reflect the variation in tetracycline usage between our sample populations.

Ciprofloxacin, norfloxacin and levofloxacin were the fluoroquinolones used in this study and their overall resistance prevalence was null. The absence of resistance of the tested clinical isolates to fluoroquinolones indicates the importance of this drug in eradicating $H$. pylori strains circulating in Cameroon. Our results is in accordance with earlier reports revealing that resistance to fluoroquinolones, particularly to levofloxacin was absent in African tested patients [39]. In contrast, the prevalence rate was higher in Europe (24.1\%) compared to Asia (11.6\%) [39]. 
No resistance prevalence was detected to rifabutin among the tested isolates. This drug is not routinely used in $H$. pylori eradication regimens, therefore finding no resistance is not unexpected. Moreover, the fact that this drug is used only in a limited number of patients to treat mycobacterial infections may also explain such low resistance rate. Our results is in accordance with some previous studies who did not find resistant among 81 stains tested in Germany [53] in 1999 and 52 strains tested in Japan [54]. However resistance rate of 1.4 and $6.6 \%$ were observed respectively among strains isolated from patients in Germany [55] and in England [56].

In the present study, $70 \%$ of the tested isolates elicited a multiple drugs resistance pattern. Double resistance with $48.57 \%$ was the more frequent, followed by triple (15.71\%) and quadruple drugs resistance (5.71\%). This multidrug resistance prevalence is higher compared to that obtained in others countries. Torres et al., [57] from Mexico have reported 30.7\% double resistance and 8.7\% triple resistance among $H$. pylori isolates. Similarly, multiple resistant strains were detected in 21 out of 252 Asiatic patients (8.3\%), in 53 out of 352 American patients (15.0\%) and in 204 out of 2272 European patients (8.9\%) [39]. In general, combined therapy including two antibiotics, and a proton pump inhibitor is used to eradicate H. pylori infection as triple therapy. As clarithromycin, metronidazole and amoxicillin are the antibiotics most frequently used, it was interesting to see if both resistances were evenly distributed. A high resistance rate of $42.14 \%$ was detected to both metronidazole and amoxicillin among the tested isolates. Since $42.14 \%$ (59/140) of the tested $H$. pylori isolates were double resistance to metronidazole and amoxicillin, recurrence $H$. pylori infection could be expected among participants receiving this combined antibiotics as therapeutic regimen. In contrast, the tested isolates elicited a resistance rate less than 5\% (4.28\%) to both metronidazole and clarithromycin, $1.42 \%$ to both metronidazole and tetracycline and $0.71 \%$ to both amoxicillin and clarithromycin. Regarding the low resistance rate of these later combined drugs, one could suggest amoxicillin/clarithromycin, metronidazole/clarithromycin, metronidazole/tetracycline with a proton pump-inhibitor as combined therapy for the treatment of $H$. pylori infection in our population, but considering the high resistance rate detected to amoxicillin and metronidazole ( 97.14 and $97.85 \%$ respectively), this cannot be proposed. Combined therapy of fluoroquinolones and tetracyclines could be used as possible agents to achieve a better eradication rate of $H$. pylori infection in these patients with regards to the absence of resistance of the tested $\mathrm{H}$. pylori isolates to fluoroquinolones (ciprofloxacin, norfloxacin and levofloxacin) and their low resistance rate to tetracyclines (tetracycline, doxycycline and minocycline).
Single and double resistance rate to both amoxicillin and metronidazole were all high among the tested $H$. pylori clinical isolates. Earlier studies have shown that amoxicillin resistance is mediated by a variety of different mechanisms including mutations in penicillin binding proteins, decreased permeability for the antibiotic $[58,59]$. Upon entering the bacterium, metronidazole is reduced to an active anion radical [60]. This forms the active compound, which acts by causing lethal damage to vital molecules such as DNA, RNA, proteins and fatty acids. An extremely low redox potential is required to allow conversion of the drug into the active form, and the cells of the host and most aerobic bacteria lack such a low redox potential [61]. Resistance to metronidazole is mediated by mutations in the rdxA gene in the majority of cases [62], leading to inactivation of the bacterial enzymes needed to activate this antibiotic [62, 63]. Moreover, frxA also been identified in resistant $H$. pylori strains. Thus, mutations in penicillin binding proteins and mutations in the rdxA and frxA genes may be responsible for the high resistance rate detected to amoxicillin and metronidazole respectively among the tested isolates, however these need to be further clarify.

Given the fact that only health centers in the most popular region of the country with high promiscuity, poor sanitation and household hygiene (factors that favour the spread of $H$. pylori) were included, extending the study sites in other region of Cameroon will improve geographic and demographic representation. Moreover, enrolling study participants in community practices will provide data on resistance rates of $H$. pylori isolates from infected persons not treated at medical centers, a population in which resistance rates in $H$. pylori are unknown and may differ significantly from the current study population. Our team are planning to take up these features.

The susceptibility of the selected MDR H. pylori isolates to antibiotics in the absence and presence of PA $\beta \mathrm{N}$ showed that this efflux pumps inhibitor have improved the activity of metronidazole, doxycycline, clarithromycin and erythromycin. In fact, in the presence of PA $\beta \mathrm{N}$, we notice a multi-fold increase in potency and in the spectrum of activity of the above antibiotics (Table 4). This observation suggested that the observed resistance pattern can be blocked by the efflux pump inhibitors that restore the intracellular concentration as well as the activities of the antibiotics [64]. Thus, overexpression of efflux pump may be the partial causative mechanism involved in the multi-drug resistance pattern elicited by the selected MDR isolates against metronidazole, doxycycline, clarithromycin and erythromycin. However others causative mechanism such as inactivation of the antibiotics or structural modification of antibiotic receptors may be also involved and could justified the non-reversibility in the activity of these antibiotics against some tested isolates. The 
activity spectrum of amoxicillin and ampicillin was not affected in the presence of inhibitors, suggested that efflux pump could not be as the causative mechanism of the observed resistance. In fact, the said drugs as $\beta$ lactam antibiotics exert their effect by disrupting the manufacture of peptidoglycan, which is main stress-bearing network in the bacterial cell wall. The disruption can occur by blocking either the construction of the subunits of the peptidoglycan or by preventing their incorporation into the existing network. Since these antibiotics acts at the level of bacterial cell wall, they could not be expel from the cell by efflux pumps mechanism.

\section{Conclusion}

Single and double resistance rate to both amoxicillin and metronidazole were all high among the tested H. pylori clinical isolates, suggesting that these drugs should be avoided as components of eradication regimen in our sample population. Considering the absence of resistance of the tested $H$. pylori isolates to ciprofloxacin, norfloxacin and levofloxacin and their low resistance rate to antibiotics from tetracycline's group, we suggest combined therapy of fluoroquinolones and tetracyclines and a proton pump inhibitor as an optimal eradication regimen for the first-line eradication of $H$. pylori infection in our milieu. Also, the administration of metronidazole, doxycycline, clarithromycin and erythromycin in combination with safety efflux pump inhibitor could be better in the management of this infection in our milieu. Ongoing, prospective surveillance of $H$. pylori resistance is essential to ensure that appropriate data are available to guide the choice of therapy, particularly in our context of highendemicity. Our further attention is focused on the genomic identification of several antibiotics resistance gene among resistant $H$. pylori clinical isolates as an approach to the surveillance of $H$. pylori resistance in Cameroon.

\section{Abbreviations \\ AMC: Co-Amoxiclav; AMO: Amoxicillin; AMP: Ampicillin; AZT: Azithromycin; $\mathrm{BHI}$ : Brain Heart Infusion; CIP: Ciprofloxacin; CLR: Clarithromycin; DOX: Doxycycline; ERY: Erythromycin; EUCAST: European Committee on Antimicrobial Susceptibility Testing; FIC: Fractional inhibitory concentration; H. pylori: Helicobacter pylori; IMP: Imipenem; LEV: Levofloxacin; MDR: Multi- drug resistance; MET: Metronidazole; MIC: Minimal inhibitory concentration; MIN: Minocycline; NOR: Norfloxacin; PAßN: Phe-Arg-naphthylamide; PEN: Penicillin; RIF: Rifabutin; RND: Resistance-nodulation-cell division; TET: Tetracycline}

\section{Acknowledgements}

We acknowledge Mr. Nangwat Claude for reading through the manuscript and editing it for language.

\section{Authors' contributions}

KMLB conceived of the study, designed the experiments and supervised the work. $\mathrm{LH}$ and KMLB provided the bacterial isolates for the study. KMLB and EBB carried out the antibiotic susceptibility test on the isolates. TZC and TNLD performed the detection of efflux pump overexpression on the selected MDR isolates. KMLB provided the facilities for the study and drafted the manuscript. All the authors read and approved the final manuscript.

\section{Funding}

No applicable.

\section{Availability of data and materials}

The datasets used and/or analyzed during the current study are available from the corresponding author on reasonable request.

\section{Ethics approval and consent to participate}

The study has been performed in accordance with the Declaration of Helsinki of 1975 and its later amendments or comparable ethical standards. The collection of biopsy specimen from dyspeptic patients was performed after obtaining an ethical approval from Laquintinie Hospital management board (Protocol number 425/ AR/ MINSANTE/ HLD/SCM/CR) and from the National Ethical Committee on Human Health Research in Cameroon (Ethical clearance $N^{0}$ 2014/03/425/L/CNESRH/SP). Participation was voluntary and each subject involved in the study gave a written consent. Children were enrolled after their parents or legal guardians received an information notice and oral explanation of the study and provided a written consent.

\section{Consent for publication}

No applicable.

\section{Competing interests}

The authors declare that they have no competing interests.

\section{Author details}

${ }^{1}$ Microbiology and Pharmacology Laboratory, Department of Biochemistry, Faculty of Science, University of Dschang, P. O. Box, 67 Dschang, Cameroon. ${ }^{2}$ Gastroenterology Department, Laquintinie Hospital of Douala, P. O. Box, 4035 Douala, Cameroon.

Received: 23 May 2019 Accepted: 9 October 2019

Published online: 22 October 2019

\section{References}

1. Sirous M, Mehrabadi JF, Daryani NE, Eshraghi S, Hajikhani S, Shirazi MH. Prevalence of antimicrobial resistance in Helicobacter pylori isolates from Iran. Afr J Biotechnol. 2011;9(36):5962-5.

2. Fallahi GH, Fallahi SM. Helicobacter pylori culture and antimicrobial resistance in Iran. Indian J Pediatr. 2007;74(2):127-30.

3. Ernst PB, Gold BD. The disease spectrum of Helicobacter pylori the immunopathogenesis of gastroduodenal ulcer and gastric cancer. Annu Rev Microbiol. 2000;54:615-40.

4. Graham DY, Qureshi WA. Antibiotic resistance H. pylori infection and its treatment. Curr Pharm Des. 2000;6:1537-44.

5. Heep M, Kist M, Strobel S, Beck D, Lehn N. Secondary resistance among 554 isolates of Helicobacter pylori after failure of therapy. Eur J Clin Microbiol Infect Dis. 2000;19:538-41.

6. Hoffman JSC, Cave DR. Treatment of Helicobacter pylori. Curr Opin Gastroenterol. 2001;1(17):30-4.

7. Gong EJE, Yun SC, Jungetal HY. Meta-analysis of first-line triple therapy for Helicobacter pylori eradication in Korea: is it time to change. J Korean Med Sci. 2014;29(5):704-13.

8. Park J, et al. Helicobacter pylori clarithromycin resistance and treatment failure are common in the USA. Digest Dis Sci. 2016;29:1-8.

9. De Francesco $V$, et al. Worldwide $H$. pylori antibiotic resistance: a systematic review. J Gastrointestin Liver Dis. December 2010;19(4):409-14.

10. Riccardo U, Rossella C, Elena RM. Update on triple therapy for eradication of Helicobacter pylori: current status of the art. Clin Exp Gastroenterol. 2012:5:151-7.

11. Rimbara E, Fischbach LA, Graham DY. Optimal therapy for Helicobacter pylori infections. Nat Rev Gastroenterol Hepatol. 2011;8:79-88.

12. Borody TJ, Shortis NP, Reyes E. Eradication therapies for Helicobacter pylori. J Gastroenterol. 1998;33:53-6.

13. Mendonca S, Ecclissato C, Sartori MS, Godoy AP, Guerzoni RA, Degger M, et al. Prevalence of Helicobacter pylori resistance to metronidazole, clarithromycin, amoxicillin, tetracycline and furazolidone in Brazil. Helicobacter. 2000;5:79-83.

14. Li XZ, Mikado H. Efflux-mediated drug resistance in bacteria. Drugs. 2004;64 159-204. 
15. Poole K. Efflux-mediated multiresistance in gram-negative bacteria. Clin Microbiol Infect. 2004;10:12-26.

16. McMurry L, Petrucci RE Jr, Levy SB. Active efflux of tetracycline encoded by four genetically different tetracycline resistance determinants in Escherichia coli. Proc Natl Acad Sci U S A. 1980;77:3974-7.

17. Kumar A, Schweizer HP. Bacterial resistance to antibiotics: active efflux and reduced uptake. Adv Drug Deliv Rev. 2005;57:1486-513.

18. Bohnert JA, Kern W. Selected Arylpiperazines are capable of reversing multidrug resistance in Escherichia coli overexpressing RND efflux pumps. Antimicrob Agents Chemother. 2005;2(49):849-52.

19. Lomovskaya O, Warren MS, Lee AJ, Galazzo R, Fronko M, Lee J, et al. Identification and characterization of inhibitors of multidrug resistance efflux pumps in Pseudomonas aeruginosa: novel agents for combination therapy. Antimicrob Agents Chemother. 2001;45:105-16.

20. Mallea MMA, Chevalier J, Alibert-Franco S, Brouant P, Barbe J, Pages JM. Alkylaminoquinolines inhibit the bacterial antibiotic efflux pump in multidrug-resistant clinical isolates. Biochem J. 2003;3(76):801-5.

21. Renau TE, Leger R, Flamme EM, Sangalang J, She MWR, Yen CL, et al. Inhibitors of efflux pumps in Pseudomonas aeruginosa potentiate the activity of the fluoroquinolone antibacterial levofloxacin. J Med Chem. 1999; 42:4928-31.

22. Thorarensen A, Presley-Bodnar AL, Marotti KR, Boyle TP, Heckaman CL, Bohanon MJ, et al. 3-Arylpiperidines as potentiators of existing antibacterial agents. Bioorg Med Chem Lett. 2001;11:1903-6.

23. Ndip RN, Malange AE, Akoachere JFT, MacKay WG, Titanji VPK, Weaver LT. Helicobacter pylori antigens in the faeces of asymptomatic children in the Buea and Limbe health districts of Cameroon: a pilot study. Trop Med Int Health. 2004;9:1036-40.

24. Ankouane Andoulo F, Noah Noah D, Tagni-Sartre M, Ndjitoyap Ndam EC, Ngu BK. Épidémiologie de l'infection à Helicobacter pylori à Yaoundé: de la particularité à l'énigme Africaine. Pan Afr Med J. 2013;16:115.

25. Ankouane Andoulo F, Ngatcha G, Tagni-Sartre M, Biwolé Sida M, Ndjitoyap Ndam EC. Helicobacter Pylori infection and peptic ulcer disease in children and adolescents from the age range of 6 to 18 years old in Yaounde (Cameroon). Health Sci Dis. 2015;16(4):1-6.

26. Kouitcheu MLB, Noudjeu MI, Leundji H. Potential risk factors and prevalence of Helicobacter pylori infection among adult patients with dyspepsia symptoms in Cameroon. BMC Infect Dis. 2018;18:278.

27. Miendje Deyi VY, Bontems P, Vanderpasetal J. Multicenter survey of routine determinations of resistance of Helicobacter pylori to antimicrobials over the last 20 years (1990 to 2009) in Belgium. J Clin Microbiol. 2011;49(6):2200-9.

28. Kouitcheu MLB, Nana BN, Eyoum BB, Tchuenteu TR, Eveline N. AntiHelicobacter pylori and antiulcerogenic activity of Aframomum pruinosum seeds on indomethacin-induced gastriculcer in rats. Pharm Biol. 2017;55(1): 929-36.

29. Clinical and Laboratory Standards Institute (CLSI). Performance standards for antimicrobial disk susceptibility tests. Wayne: CLSI document; 2015. p. M02-A12.

30. Clinical and Laboratory Standards Institute. Performance standards for antimicrobial susceptibility testing, twentieth informational supplement. Wayne: CLSI document; 2012. p. M100-S22.

31. Comité de l'antibiogramme de la société Française de microbiologie (CASFM). Recommandation 2017. p.117. www.sfm-microbiologie.org. Accessed 11 May 2017.

32. Braga LC, Leite AAM, Xavier KGS, Takahashi JA, Bemquerer MP, ChartoneSouza E, et al. Synergic interaction between pomegranate extract and antibiotics against Staphylococcus aureus. Can J Microbiol. 2005;51(7):541-7.

33. Mativandlela SPN, Lall N, Meyer JJM. Antibacterial, antifungal and antitubercular activity of (the roots of) Pelargonium reniforme (CURT) and Pelargonium sidoides (DC) (Geraniaceae) root extracts. S Afr J Bot. 2006; 72(2):232-7.

34. Brigitte KML, Bille BE, Nguepi E. In Vitro and In Vivo anti-helicobacter activities of Eryngium foetidum (Apiaceae), Bidens pilosa (Asteraceae), and Galinsoga ciliata (Asteraceae) against Helicobacter pylori. Biomed Res Int. 2016;2016:2171032 7 pages.

35. EUCAST. EUCAST clinical breakpoints for Helicobacter pylori; 2011. http:// www.eucast.org/fileadmin/src/media/PDFs/EUCAST_files/Breakpoint_tables/ Breakpoint_table_v_4.0.pdf

36. King A. Recommendations for susceptibility tests on fastidious organisms and those requiring special handling. J Antimicrob Chemother. 2001;48(1):77-80.
37. Ndip RN, Malange Takang AE, Ojongokpoko JE, et al. Helicobacter pylori isolates recovered from gastric biopsies of patients with gastro-duodenal pathologies in Cameroon: current status of antibiogram. Trop Med Int Health. 2008;13:848-54.

38. Seck A, Mbengue M, Gassama-Sow A, Diouf L, Ka MM, Boye CS. Antibiotic susceptibility of Helicobacter pylori isolates in Dakar, Senegal. J Infect Dev Ctries. 2009;3:137-40.

39. De Francesco V, Floriana G, Cesare H, Gianpiero M, Lucy V, Carmine $P$, et al. Worldwide H. pylori antibiotic resistance: a systematic review. J Gastrointestin Liver Dis. 2010;19(4):409-14.

40. Boyanova L, llieva J, Gergova G, et al. Evaluation of clinical and sociodemographic risk factors for antibacterial resistance of Helicobacter pylori in Bulgaria. J Med Microbiol. 2009:58:94-100.

41. Bruce MG, Bruden DL, McMahon BJ, et al. Alaska sentinel surveillance for antimicrobial resistance in Helicobacter pylori isolates from Alaska native persons, 1999-2003. Helicobacter. 2006;11:581-8

42. Kato S. Helicobacter pylori eradication therapy in children. Nippon Rinsho. 2009;67:2311-6.

43. Kim N, Kim JM, Kim CH, et al. Institutional difference of antibiotic resistance of Helicobacter pylori strains in Korea. J Clin Gastroenterol. 2006;40:683-7.

44. Hung KH, Sheu BS, Chang WL, Wu HM, Liu CC, Wu JJ. Prevalence of primary fluoroquinolone resistance among clinical isolates of Helicobacter pylori at a University Hospital in Southern Taiwan. Helicobacter. 2009;14:61-5.

45. De Francesco V, Margiotta M, Zullo A, et al. Prevalence of primary clarithromycin resistance in Helicobacter pylori strains over a 15 year period in Italy. J Antimicrob Chemother. 2007:59:783-5.

46. Agudo S, Alarcón T, Cibrelus L, Urruzuno P, Martínez MJ, López-Brea M. High percentage of clarithromycin and metronidazole resistance in Helicobacter pylori clinical isolates obtained from Spanish children. Rev Esp Quimioter. 2009:22:88-92.

47. Siavoshi F, Pourkhajeh AH, Merat SH, Asl-Soleimani H, Heydarian E, Khatibian $\mathrm{M}$, et al. Susceptibility of various strains of Helicobacter pylori to selected agents. Arch Iran Med. 2000;3:60-3.

48. Falsafi T, Mobasheri F, Nariman F, Najafi M. Susceptibilities to different antibiotics of Helicobacter pylori strains isolated from patients at the pediatric medical Center of Tehran, Iran. J Clin Microbiol. 2004;42:387-9.

49. Petersen AM, Gjøde P, Vinge OD, Jensen S, Krogfelt KA. Helicobacter pylori antimicrobial resistance and risk factors in Denmark 1998-2004: no need for concern? Helicobacter. 2006;11:210-1.

50. Zullo A, Perna F, Hassan C, et al. Primary antibiotic resistance in Helicobacter pylori strains isolated in northern and Central Italy. Aliment Pharmacol Ther. 2007;25:1429-34.

51. Wolle K, Leodolter A, Malfertheiner P, Konig W. Antibiotic susceptibility of Helicobacter pylori in Germany: stable primary resistance from 1995 to 2000. J Med Microbiol. 2002;51:705-9.

52. Vallejos C, Garrido L, Cáceres D, et al. Prevalence of metronidazole, clarithromycin and tetracycline resistance in Helicobacter pylori isolated from Chilean patients. Rev Med Chil. 2007;135:287-93

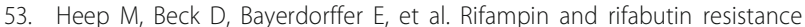
mechanism in Helicobacter pylori. Antimicrob Agents Chemother. 1999; 43:1497-9.

54. Fujimura S, Kato S, Kawamura T, et al. In vitro activity of rifampicin against Helicobacter pylori isolated from children and adults. J Antimicrob Chemother. 2002;49:541-3.

55. Glocker E, Bogdan C, Kist M. Characterization of rifampicin-resistant clinical Helicobacter pylori isolates from Germany. J Antimicrob Chemother. 2007;59:874-9.

56. Chisholm SA, Teare EL, Davies K, Owen RJ. Surveillance of primary antibiotic resistance of Helicobacter pylori at centres in England and Wales over a sixyear period (2000-2005). Euro Surveill. 2007;12:E3-4.

57. Torres J, Camorlinga-Ponce M, Perez-Perez G, Medrazo-De la Garza A, Dehesa M, Gonzalez-Valencia G, et al. Increasing multidrug resistance in Helicobacter pylori strains isolated from children and adults in Mexico. J Clin Microbiol. 2001;39:2677-80.

58. Malfertheiner P, Megraud F, O'Morain CA, Atherton J, Axon AT, Bazzoli F, et al. Management of Helicobacter pylori infection--the Maastricht IV/ Florence consensus report. Gut. 2012;61(5):646-64.

59. Qureshi NN, Gallaher B, Schiller NL. Evolution of amoxicillin resistance of Helicobacter pylori in vitro: characterization of resistance mechanisms. Microb Drug Resist. 2014;20(6):509-16.

60. Edwards DI. Nitroimidazole drugs -action and resistance mechanisms. I. Mechanisms of action. J Antimicrob Chemother. 1993;31:9-20. 
61. Wangnamou M, Kouitcheu Mabeku LB, Eyoum BB, Tamesse JL, Etoa F-X. Antibiotic minimum inhibitory concentrations and time-killing against Helicobacter pylori clinical isolates in Douala, Cameroon: therapeutic potential of routinely antibiotics. Int J Pharm. 2018;8(2):1-10.

62. Goodwin A, Kersulyte D, Sisson G, Veldhuyzen van Zanten SJ, Berg DE, Hoffman PS. Metronidazole resistance in Helicobacter pylori is due to null mutations in a gene ( $r d \times A)$ that encodes an oxygen-insensitive NADPH nitroreductase. Mol Microbiol. 1998;28(2):383-93.

63. Jenks PJ, Edwards DI. Metronidazole resistance in Helicobacter pylori. Int J Antimicrob Agents. 2002;19(1):1-7.

64. Page's J-M, Amaral L. Mechanisms of drug efflux and strategies to combat them: challenging the efflux pump of gram-negative bacteria. Biochim Biophys Acta. 2009;1794:826-33.

\section{Publisher's Note}

Springer Nature remains neutral with regard to jurisdictional claims in published maps and institutional affiliations.

Ready to submit your research? Choose BMC and benefit from:

- fast, convenient online submission

- thorough peer review by experienced researchers in your field

- rapid publication on acceptance

- support for research data, including large and complex data types

- gold Open Access which fosters wider collaboration and increased citations

- maximum visibility for your research: over $100 \mathrm{M}$ website views per year

At BMC, research is always in progress.

Learn more biomedcentral.com/submissions 